\title{
Portfólio como dispositivos metodológicos: os saberes (auto) biográficos da formação
}

\author{
Aurea da Silva Pereira \\ Universidade do Estado da Bahia - UNEB
}

\begin{abstract}
Resumo
Este artigo discute as aprendizagens construídas no processo formativo de Estágio em sala de aula. O recorte apresentado faz parte do projeto de pesquisa Estágio de Letras na Formação de Professores de Língua Portuguesa: retratos, imagens e registro de narrativas, portfólios e memoriais. O estudo teve início em 2012 com a participação de dois bolsistas. A investigação apropria-se dos pressupostos teóricos da pesquisa qualitativa, com suporte documental, analisando memoriais e portfólios. Para a elaboração deste texto, utilizou-se um portfólio de aprendizagem escrito por um estudante-estagiário que narra experiências formativas de estágio II - denominada Oficina de Intervenção. As narrativas registradas oportunizam observar as aprendizagens, promovendo reflexão acerca das práticas pedagógicas vividas na sala de aula.

Palavras-chave: Narrativas de estágio. Portfólios. Aprendizagens.
\end{abstract}

\begin{abstract}
This article discusses the learning built in the formative process of internship in the classroom. The clipping presented is part of the research project Supervised practice of Letters in the Portuguese Language Teacher Training: portraits, images and record of narratives, portfolios and memorials. The study began in 2012 with participation of two University scholarship students. The research appropriates the theoretical assumptions of qualitative research, with documental support, analyzing memorials and portfolios. For this writing, we used a learning portfolio written by a trainee/student that narrates formative experiences of second Supervised practice - called Intervention Workshop. The recorded narratives allow to observe the learning, promoting reflection on the pedagogical practices lived in the classroom.
\end{abstract}

Keywords: Internship narratives. Portfolios. Learning.

\section{CONTEXTUALIZAÇÃO DA PESQUISA}

Pretende-se, neste texto, apresentar e discutir as aprendizagens construídas no processo de Estágio em sala de aula. O recorte do estudo abordado faz parte do Projeto de Pesquisa Estágio de Letras na Formação de Professores de Língua Portuguesa: retratos, imagens e registro de narrativas, portfólios e memoriais. A investigação teve início em 2012 com a participação de dois bolsistas do Programa de Iniciação Científica 
da Universidade do Estado da Bahia - PICIN /UNEB. Tomou-se como objeto de estudo, narrativas autobiográficas que constituem os portfólios e memoriais de estudantesprofessores graduandos de Língua Portuguesa do curso de Letras do Campus II, do Departamento de Educação - DEDC da UNEB, construídos durante o período de estágio.

A idealização da proposta de portfólios e memoriais como dispositivos metodológicos, no Estágio Supervisionado, começou a ser delineada entre os anos de 2008 a 2009, quando comecei, com os estudantes, as leituras das narrativas. Porém, inicialmente, o objetivo era puramente avaliativo, pois desejava saber como estes se percebiam no processo de escrita de si mesmos acerca do estágio. As narrativas me surpreendiam cada vez mais, e eu não sabia que o material se constituiria em documentos para além do estágio: fontes de pesquisa para formação docente e um contributo teórico-metodológico para estudantes-estagiários, professores supervisores e orientadores de Estágio.

$\mathrm{Na}$ condição de professora, orientadora e supervisora de estágio, comecei a experimentar os portfólios e memoriais como dispositivos teórico-metodológico na formação inicial da docência: o Estágio. As narrativas que compõem os portfólios permitiam/permitem aos estudantes em iniciação docente falar de si, escrever sobre si e sua práxis nesta etapa. $\mathrm{O}$ ato de escrever sobre si, na elaboração do portfólio e do memorial, é um modo de revelar-se, com a finalidade de dizer quem é, como tem pensado a docência e o porquê das escolhas no processo formativo como esclarece Pereira (2013), que explica ainda:

[...]tomamos a escrita autobiográfica como eixo metodológico como forma de propiciar espaços e estratégias que permita a cada estudante e professor formador a pensar sobre sua trajetória pessoal, acadêmica e profissional. E a construção de portfólios e memoriais como gêneros textuais e instrumentos que permitem que as estudantes escrevam suas percepções, crises, aulas, dilemas, inferências e estratégias construídas nesse processo de auto formação e construam suas histórias de discentes e docentes. Ao narrar sobre si, o/a estudante se constitui como autor/pesquisador e ao mesmo tempo, ele se convoca a se responsabilizar sobre o ato de escrever e dizer sobre si. (PEREIRA, 2013, p. 187).

As narrativas, como dito, me instigavam e comecei a pensar sobre um projeto de pesquisa com o qual pudesse estudar os portfólios, erigidos a partir das histórias narradas pelos estudantes-estagiários. Diante das experiências com tais relatos e da análise do material, na condição de professora de Estágio Supervisionado, elaborei esta proposta, submetendo-a à avaliação do Pró-Reitoria de Pesquisa e Ensino na graduação 
e pós-graduação, bem como ao Comitê de Ética da Universidade do Estado da Bahia, tendo como premissa que:

\begin{abstract}
A escolha por portfólios se dá por entendermos que se trata de uma estratégia didática de aprofundamento do conhecimento sobre o processo ensinoaprendizagem e natureza reflexiva, colaborativa e interpessoal dos processos de construção do conhecimento. Acreditamos que o registro pontual e reflexivo das aulas/atividades/reflexões narradas no portfólio dão subsídios para um olhar de si no ato de narrar e registrar os acontecimentos da prática docente; além disso, permite a construção do retrato pedagógico na sala de aula. (PEREIRA, 2013, p. 187).
\end{abstract}

A escrita de si conta, narra e reflete as aprendizagens pedagógicas e linguísticas no processo de formação inicial. As narrativas registradas nos portfólios faz com que os estudantes debrucem sobre si e teçam as dificuldades pedagógicas, visando traçar estratégias didáticas para alcançar os objetivos propostos nos planos de aula. Nos portfólios, os estudantes-estagiários registram as aulas, narrando-se, apresentando episódios captados no processo interativo pedagógico. Como pontua Bastos (2015, p.62) “Os portfólios de aprendizagem são dispositivos que permitem captar a singularidade de cada docente, em formação inicial, durante o processo de formação superior".

No trajeto da atuação no campo de estágio, enquanto professora/pesquisadora/orientadora/supervisora, tenho observado diversos questionamentos, a saber: (a) como se configura o estágio no curso de Letras? (b) como os professores se apropriam das teorias e elaboram e reelaboram sua prática pedagógica? (c) como os professores de Língua Portuguesa ressignificam os saberes teóricos e os saberes da experiência no cotidiano escolar? (d) Quais os sentidos das aprendizagens do Estágio?

Questões desta natureza põem em debate o currículo do curso de Letras e seu papel na formação pedagógica, intelectual e política, e as contribuições do Estágio Supervisionado como componente que tem um diálogo permanente com a educação básica. Também corroboram com Lima (2012, p.29) que espera, com o Estágio, enquanto espaço de pesquisa, "contribuir na formação de professores críticos-reflexivos, competentes, comprometidos e cientes de sua função social".

Logo, neste caso, pesquisar sobre a contribuição do Estágio de Letras e sua práxis na formação profissional no âmbito da pesquisa e da docência, implica investigar os saberes construídos na pesquisa, no ensino e na extensão, por meio do diálogo estabelecido e construído do Estágio I ao IV em Língua Portuguesa e Literaturas do 
Curso de Letras do Campus II - UNEB, município de Alagoinhas (BA). De acordo com Pereira (2013, p. 182):

Há tempos temos nos perguntado sobre a função política, social e educacional do Estágio na formação docente dos cursos de licenciaturas. Somos nós professores de Estágio que acompanhamos estudantes dos cursos de Licenciaturas nas escolas. Somos nós que propomos o diálogo entre a escola e a universidade. Por outro lado, somos nós que experienciamos as crises entre as escolhas, os espaços de educação, planejamentos. Somos nós também que recebemos e-mails que dizem assim: "Professora eu não desejo ser professora de ensino fundamental e médio, por favor, me arrume outro lugar para fazer o estágio; Professora, eu não quero mais ficar naquela sala de aula, a regente me deixou só...” Entre outras questões, temos também os outros componentes curriculares junto com o componente estágio; ou apenas uma falsa aparência de que o estágio se configura apenas como cumprimento de carga horária.

Tais questionamentos, destacados por Pereira (2013), fortaleceram decisões de modo a pensar em dispositivos metodológicos que oportunizassem a cada estudanteestagiário o acesso a si mesmo e à sua práxis de formação na docência, a partir de narrativas formativas, pois como frisado por Delory-Momberger (2008, p. 56): “A narrativa (auto) biográfica instala uma hermenêutica da 'história de vida', isto é, um sistema de interpretação e de construção que situa, une e faz significar os acontecimentos da vida como elementos organizados no interior de um todo". Além disso, como menciona Bolívar (2012, p. 40-41):

\footnotetext{
Em sua grande obra Tempo e Narração, Ricoeur (1995) faz uma hermenêutica da consciência histórica sublinhando o valor produtivo ("poiético") da história para reapresentar ("mimesis") a ação, transformandoa - por supostamente enorme ou significante - em uma intriga. A mediação entre as histórias históricas e as histórias de ficção é a história da nossa própria vida: "a história contada diz quem da ação. A identidade da pessoa que não é mais uma identidade narrativa". A hermenêutica dos textos permite fazer - através da história - hermenêutica da vida humana. Dessa forma, o modelo abrangente de Ricoeur fornece fundamentos epistemológicos para a construção de histórias de vida. (Tradução nossa).
}

As pessoas são dotadas de competências para se narrar. Aliás, uma parte de nossa vida consiste em contar histórias e refleti-las. Ao narrar episódios e ações, conjeturamos sobre aprendizagens pedagógicas e nos reconhecemos como responsável ou corresponsável por estas, fundamentando-as nas teorias estudadas na universidade e mobilizando-as para atos didáticos no processo de ensino e aprendizagem em sala de aula. Esses registros ganham poder nas narrativas, potencializando conhecimentos acerca de si mesmo e do contexto pedagógico e acadêmico. Isto é, avaliando-se e, paralelo a isso, percebendo-se como professor. Passeggi (2012, p. 41-42) observa: 
Uma criança de 05 (cinco) anos pode nos dizer: "Quando eu era pequeno eu não gostava de tomates"; "Quando eu crescer, eu quero ser grande". Mediante essas pequenas narrativas, a criança se desdobra como objeto de reflexão e como ser reflexivo; coloca-se em cena como espectador e espetáculo; observa-se, avalia-se, projeta-se como espectador e objeto pensado. É essa a dialética entre ser e a representação do ser, mediada pela interpretação, nas narrativas de si, que nos permite falar de reflexividade autobiográfica.

A interpretação de si diante da própria representação, permite que cada pessoa se perceba, fazendo um balanço de como se tornou o que é hoje e como se predita para o futuro. No entender de Passeggi (2012, p. 43) "Mediante a linguagem e a narrativa é possível reabrir o passado e se projetar em devir". Ao biografar as próprias narrativas, o estudante-estagiário se apropria do tempo cronológico e psicológico, colocando-o num tempo humano presente, atualizando o passado.

\section{PRESSUPOSTOS TEÓRICO-METODOLÓGICOS DA PESQUISA - NARRATIVAS AUTOBIOGRÁFICAS" NOS PORTFÓLIOS DE APRENDIZAGENS}

A leitura e a análise das narrativas, em estudo, buscaram, assim, a teoria da interpretação de Ricoeur (1976) como perspectiva epistemológica para interpretar as categorias que emergem das "questões-problema" da pesquisa e da proposta metodológica do campo de Estágio, bem como dos objetivos alvitrados através da investigação do objeto em análise. A apreciação das narrativas tem por base a compreensão de si mesmo, de como o estudante-estagiário se reconhece no percurso formativo da docência. Por isso, para análise das fontes coletadas, utilizamos a trama interpretativo-compreensiva de Ricoeur (1976) e a análise compreensiva sugerida por Bertaux (2010). Além disso, apropriamo-nos da pesquisa documental por utilizar dados que se constituem uma fonte rica de informações, explicada pelo uso da técnica documental nas áreas das Ciências Humanas e Sociais (CELLARD, 2008). Esse tipo de análise cria possibilidades de ampliar a compreensão acerca do objeto de estudo.

A pesquisa documental se constitui num método que utiliza a apreensão, compreensão e análise de documentos diversos. Faz-se necessário ainda pontuar que o documento como fonte de pesquisa não precisa necessariamente ser escrito ou impresso. Numa pesquisa documental podemos incluir filmes, vídeos, slides, fotografias ou pôsteres. Tais documentos podem ser utilizados como fonte de informações. No caso desta pesquisa, usamos Portfólios de aprendizagem, isto é, documentos oficiais de 
Estágio de Letras. Para o trabalho ora apresentado foi considerado apenas um portfólio, elaborado no semestre 2012-1.

Os Portfólios permitem ao estudante-estagiário "avaliar a si próprio, tendo como parâmetro sua condição inicial de aprendizagem, sendo capaz de visualizar as conquistas, os desafios e, ao mesmo tempo, as reais potencialidades [...]”, conforme destacam Almeida, Gomes e Tinós (2011, p.210). Isso porque, refletir sobre o próprio processo de aprendizagem contribui para transformar e melhorar aquilo que ainda falta, bem como a valorizar avanços, valendo-nos da premissa de que somos sujeitos em constante processo de mudança e corresponsáveis pelos progressos e entraves. Ainda de acordo com Almeida, Gomes e Tino (2011, p. 210):

\begin{abstract}
[...] portfólio de aprendizagem constituiu na elaboração de uma auto e uma heteroavaliação, de maneira que cada um pudesse, ao mesmo tempo, se ver e ver o outro, o seu par, em todo o itinerário em que esteve implicado. Com tal procedimento, mediante a metacognição como processo de autorregulação da aprendizagem, de relações construídas entre causas e consequências, buscamos garantir a globalidade da aprendizagem. Avaliar a si próprio, tendo como parâmetro sua condição inicial de aprendizagem, sendo capaz de visualizar as conquistas, os desafios e, ao mesmo tempo, as reais potencialidades, foi um procedimento útil nessa etapa do trabalho.
\end{abstract}

As narrativas que constituem os portfólios, oportunizam ao estudante-estagiário a auto avaliação de sua prática docente, tendo a oportunidade de interpretar-se, analisarse, reescrever-se e inscrever-se como objeto de estudo de sua formação. Os fenômenos que acontecem na sala de aula estão/estarão presente nas autobiografias do modo como cada estudante-estagiário se percebeu no processo.

Os portfólios são constituídos por narrativas autobiográficas, planos de aulas, atividades escritas, exercícios, textos produzidos pelos estudantes da educação básica das escolas públicas do município de Alagoinhas (BA). Nas narrativas do portfólio em estudo, adotou-se nome fictício, a fim de preservar a imagem pessoal, acadêmica e profissional do autor.

As narrativas construídas no processo de formação docente consentem um olhar sobre sua construção identitária da docência, imbricada na profissionalização e construção dessa identidade. Não há projeto de formação que não esteja entrelaçado com a identidade de cada um. O excerto textual retirado do portfólio do estudanteestagiário Paulo, apresenta a primeira experiência na docência, o Estágio Supervisionado II. Nesse Estágio, os estudantes organizam oficinas de intervenção pedagógica com base na pesquisa realizada durante o Estágio I, concebido como Estágio de observação. 
Logo que chegamos à sala de aula nos apresentamos para os alunos, explicando o motivo de estarmos ocupando a aula de Língua Portuguesa e, ao mesmo tempo, situando-os a respeito da regulamentação da Lei 10.639, que estabelece como norma o ensino da cultura afro-brasileira na escola. [...] Lemos um conto sobre racismo que retiramos da internet, de autoria desconhecida, pois propositalmente não providenciamos cópias para eles, uma vez que objetivávamos também a prática de escuta de textos literários [...] Para nossa surpresa, entretanto, durante a leitura do poema todos os estudantes estavam atentos, de ouvidos bem abertos para o que estava sendo lido, o que já me deixava contente. Ainda que no fim da leitura eles dissessem que não haviam entendido nada, ficaria contente pelo fato de terem escutado a leitura. Ao término da leitura, mais uma feliz surpresa: todos os alunos bateram palmas. Eu pensei: meu Deus eles bateram palmas! Isso mesmo eles bateram palmas e, se tomaram essa atitude, foi porque gostaram e se gostaram foi porque entenderam a mensagem. A partir desse momento, para mim, a oficina já tinha superado minhas expectativas. Pensei que os estudantes teriam dificuldades de concentração, pois afinal a turma desde sempre tinha se mostrado inquieta, mas foi justamente o contrário. A turma foi bastante participativa, discutiu o tema, trouxe exemplos do cotidiano, enfim, interagiu muito conosco. Esse momento de debate me fez perceber que nós, ainda que na posição de professores, temos muito a aprender com nossos alunos. Sempre escutei isso, mas sem dar muito crédito, mas através desse primeiro dia de oficina pude ver que, mesmo com pouca idade, eles efetivamente têm o que nos ensinar e que nós, sem sombra de dúvidas, podemos aprender com eles. Digo isso, pois durante esse momento de discussão do texto um dos alunos, Vinícius, sinalizou algo que no texto eu não tinha notado e que, sem dúvida, contribuiu muito para o enriquecimento das discussões. Além disso, me senti muito acolhido e respeitado pela turma. Me senti muito confortável. (PAULO, 2012-1).

Observa-se como o estudante-estagiário narra uma de suas primeiras experiências de estágio. Ele se apresenta e vai se constituindo professor enquanto se expõe no processo de mediação pedagógica. Munido de vontade, desejos e muitas expectativas em corresponder ao planejamento da oficina, a leitura de texto sobre o racismo no Brasil, ao que parece, rendeu muitas discussões na aula e supriu as expectativas do estudante-estagiário. Percebe-se que a identidade docente é demarcatória na narrativa ao se colocar sempre na primeira pessoa do plural, envolvendo a colega que realizou a oficina com ele. As aprendizagens construídas no processo interativo com os estudantes demonstram e garantem a mobilização dos conteúdos presentes no texto sobre racismo. Pode-se afirmar que "[...] os processos formativos pessoais e os processos formativos profissionais constroem-se mutuamente à formação de um sujeito - é a sua inserção em um mundo conceitual e prático" (FÁVERO; TONIETO, 2010, p. 29). Entretanto, como pontua Schön (2000, p.131):

É sempre difícil dizer o que um estudante finalmente aprendeu a partir da experiência de uma aula prática reflexiva. É especialmente difícil dizer, o que [...] não aprendeu, porque a experiência do ensino prático pode criar raízes no subsolo da mente, na frase de Dewey, supondo significados sempre novos no decorrer do desenvolvimento de uma pessoa. 
A aprendizagem construída em uma aula prática torna-se significativa à medida em que o estudante tem uma nova experiência, num novo contexto pedagógico. Ao perceber o que está em seu entorno e o que há de diferente nessa nova aula, o estudanteestagiário pode avaliar-se e refletir sobre as aprendizagens, bem como acerca dos desafios que ainda precisa enfrentar, como evidencia a aula realizada em outro espaço pedagógico:

$\mathrm{Na}$ segunda parte da oficina, levamos duas notícias que traziam como manchete o racismo cometido contra pessoas negras na atualidade, cujos títulos eram: Senador italiano compara ministra negra a orangotango e Montagem compara vereadora negra e travesti de Piracicaba a chimpanzé, ambas retiradas do site de notícias G1. A proposta inicial era que os estudantes, divididos em dois grupos, pudessem ler e discutir a notícia entre si e, posteriormente, lê-la para toda a turma, buscando apresentar a situação problema trazida pela reportagem, de maneira que todos pudessem compreender que as práticas de racismo, esteriotipação e desvalorização da figura do negro não são algo do passado e ainda se perpetuam nos dias atuais. [...] Após o momento de leitura, os estudantes puderam argumentar contra ou a favor ao conteúdo da notícia. De imediato, eles se colocaram contra as práticas de racismo que estavam sendo noticiadas, buscando argumentar da melhor maneira possível. Nossa oficina não tinha nenhuma relação direta com as redes sociais, muito menos com o Facebook. Entretanto, as discussões sobre esta rede de relacionamento nos fez sugerir que as discussões em sala de aula pudessem ser levadas por eles para as redes sociais, em especial o Facebook, realizando, assim, uma corrente contra as práticas de racismo e outras formas de desrespeito contra as pessoas negras. Com isso aprendi que uma aula pode ir além daquilo que planejamos, e creio que os estudantes talvez tenham percebido as aulas de Português para além da sala de aula. (PAULO, 2012.1).

O estudante-estagiário descreve em sua narrativa estratégias para realização da atividade didática e apresenta os resultados com encaminhamentos e reflexões, propondo a se pensar de fato na função da aula de Português. Vê-se que aula está imbricada numa prática reflexiva do fazer docente. Para Schön (2000, p.133): “Um ensino prático reflexivo é uma experiência de alta intensidade interpessoal" que merece levar em conta a realidade cultural e social dos estudantes, bem como a vulnerabilidade e os diversos comportamentos presentes na sala de aula. Percebe-se que os saberes discentes ganharam outros sentidos e o estudante-estagiário assumiu a docência mobilizando os discentes para sua ação pedagógica, transformando-os em pactos e estratégias de combate ao racismo nas redes sociais.

Em razão disso, não podemos pensar educação e escola, sem considerar o perfil do professor que nela irá atuar, pois ele é o ingrediente principal para a construção da nova identidade escolar. Para Libâneo (2004, p. 7) “[...] não há reforma educacional, 
não há proposta pedagógicas em professores, já que são os profissionais mais diretamente envolvidos com os processos e resultados da aprendizagem escolar".

A realidade e o ambiente educativo nos quais os estudantes-estagiários realizam suas práticas de estágio deveriam ter o papel político e pedagógico de discutir, propor questões e repensar atitudes preconceituosas vividas no ambiente escolar. Muitas destas consideradas normais pelos professores-regentes, como se pode observar no excerto textual a seguir:

\begin{abstract}
Terminada a atividade, nos arrumávamos todos para sair da sala e logo os meninos e meninas começaram a devolver os textos que havíamos entregue para a realização da atividade. Logo que percebi que tais textos estavam sendo devolvidos, falei com a professora que seria bom que os estudantes ficassem com os textos, que não havia necessidade de devolver. Para minha infeliz surpresa, a professora me respondeu que não, que não deveríamos dar os textos aos estudantes. Se nós não os quiséssemos, podíamos dar a ela, mas aos estudantes não, porque iriam, segundo ela, rasgar, e não teriam cuidado, enfim não saberiam como utilizar. Neste momento a fala da professora me pareceu agressiva, como se ela tivesse chamando os estudantes de selvagens. Entretanto, este modo de falar me pareceu grosseiro, não foi nada comparado a ótima discussão e participação dos estudantes durante toda a realização das atividades. (PAULO, 2021-1).
\end{abstract}

Observa-se como a atitude da professora-regente chocou a concepção de educação e formação do estudante-estagiário. Como os textos podem ser negados aos estudantes? O pensamento da professora está arraigado numa concepção de mundo etnocêntrico e de hierarquização dos saberes e valores incutidos na sociedade. Logo, a professora-regente propõe que os textos deveriam ficar com os professores e não com os estudantes. “A realidade, o ambiente educativo e a própria noção de ser humano são do ponto de vista técnico-instrumental-comportamentalista, fenômenos objetivos que podem ser manipulados por meio de intervenções e controle do ambiente" (FÁVERO; TONIETE, 2010, p. 43).

São nestes espaços educativos que os estudantes-estagiários vão se constituindo, reconstruindo valores e identidade e, ao mesmo tempo, se inscrevendo como professor. E, se "não cair na cilada da burocracia curricular escolar", o professor estagiário poderá escrever outra escola - um espaço educativo prazeroso para todas as classes sociais. Porém, é preciso ter determinados cuidados com nossos discursos, bem como gêneros textuais que levamos para o ambiente escolar, pois como aponta Delory-Momberger (2008, p. 117): 
$\mathrm{Na}$ experiência que as crianças e os adolescentes têm da escola, os signos e os discursos segundo os quais se diz e se lê o mundo constituem um dos primeiros campos de conflito entre mundo-da-vida e a cultura escolar. De fato, a escola é, por excelência, um lugar de produção de signos e de discursos: tudo o que é ensinado, aprendido, avaliado na escola, é feito por signos.

Por outro lado, "os professores não conseguem refletir concretamente sobre mudanças porque são eles próprios condicionados ao contexto que atuam”, como esclarece Pimenta (2002, p. 23). Porém, mesmo sabendo que "não há transparência, inocência, neutralidade na cultura escolar”, como sublinha Delory-Momberger (2008, p. 119), o espaço educativo está sujeito a mudanças, contornos e tons impregnados de signos e símbolos que propõem a reflexão e a ressignificação do mundo e da vida cotidiana. Em pouco tempo, o estudante-estagiário conseguiu perceber a participação e envolvimento dos estudantes na atividade realizada, pois se tratava de uma realidade vivida nas escolas públicas brasileiras, como a questão do racismo. Assim, corrobora-se com Lima (2012, p. 37) ao afirmar que “o Estágio como espaço e processo aberto contextualizado - permite elaborar uma nova cultura emergente na ação docente".

A escrita das narrativas autobiográficas sobre as aulas de Estágio propõe ao estudante-estagiário pensar na sua formação acadêmica e no professor que pretende se tornar, conduzindo-o à reflexão da ação da pedagógica. De tal modo, tomando como parâmetro a etnografia ${ }^{1}$ da escola e as práticas pedagógicas em sala de aula, eles constroem projetos de intervenção pedagógica no Estágio Supervisionado II, durante as oficinas. A escrita do Estágio possibilita refletir sobre o Estágio enquanto espaço de formação e aprendizagem na construção do processo identitário, pois, como afirma Nóvoa (2000, p. 10), “todo conhecimento é autoconhecimento, toda formação é autoformação". Isso fica evidente em Delory-Momberger (2008, p.36), ao discutir a importância das narrativas autobiográficas no processo de formação docente:

\begin{abstract}
O ser humano apropria-se de sua vida e de si mesmo por meio de histórias. Antes de contar essas histórias para comunicá-las aos outros, o que ele vive só se torna sua vida e ele só se torna ele mesmo por meio de figurações com as quais representa sua existência. A primeira dessas figurações, a mais matriarcal e abrangente, aquela que de certa forma enquadra a infinita multiplicação das histórias humanas, concerne ao desenrolar da vida. Tanto na sua linguagem mais coloquial quanto nas criações mais elaboradas, os homens recorrem às palavras e imagens que transpõem para uma representação espacial o desenvolvimento temporal de sua existência: linha, fio, caminho, trajeto, estrada, percurso, círculo, carreira, ciclo de vida. O homem escreve no espaço a figura de sua vida.
\end{abstract}

\footnotetext{
${ }^{1}$ No Estágio de Observação, realizado no Estagio Supervisionado I, os estudantes-estagiários pesquisam a escola, o projeto pedagógico e as salas de aula, construindo uma etnografia escolar.
} 
Narrar-se sobre o processo formativo é contar para si como está sendo experimentada a prática pedagógica de Estágio na sala de aula e, ao mesmo tempo, refletir sobre as aprendizagens de si, da docência e práticas educativas experienciadas. Além disso, como dito por Josso (2004, p. 43):

[...] a narrativa de um percurso intelectual e de práticas de conhecimento põe em evidência os registros da expressão dos desafios de conhecimento ao longo de uma vida. Esses registros são precisamente os conhecimentos elaborados em função de sensibilidades particulares em um dado período.

Esse dispositivo metodológico dá “[ [...] ao (futuro) professor as chaves para o acesso ao processo histórico de sua formação, aos conhecimentos implícitos e as novas formas de aprendizagem" (PASSEGGI, 2008, p. 43).

\section{CONSIDERAÇÕES FINAIS}

Portanto, conclui-se que narrar sobre si é construir conhecimentos implícitos e novas aprendizagens. Por intermédio da escrita de si, o sujeito tem a oportunidade de refletir sobre seu processo formativo, pois como afirma Souza (2006, p. 102):

[...] a arte de lembrar remete o sujeito a observar-se numa dimensão genealógica, como um processo de recuperação do eu, e a memória narrativa marca um olhar sobre si em diferentes tempos e espaços, os quais se articulam com as lembranças e as possibilidades de narrar às experiências.

A discussão apresentada neste artigo traz contribuições ao debate, tendo como pressupostos as pesquisas que vêm sendo realizadas na área de Educação e em nosso grupo de estudo. Percebemos que, na sociedade contemporânea, o ensino de graduação nos cursos de licenciatura tem sido submetido aos mecanismos do mercado e os estudantes, muitas vezes, não se percebem como sujeitos em formação profissional. Por conta disso, o processo formativo da docência fica em segundo plano, porque há outras disciplinas teóricas que ganham notoriedade em detrimento das disciplinas de Prática Pedagógica e Estágio Supervisionado.

Assim sendo, "na contramão dessa perspectiva entendemos que é preciso se criar uma cultura acadêmica nos cursos de graduação na universidade", garantindo aos estudantes/estagiários "o direito de acesso a uma formação que garanta aos estudantes o desenvolvimento de uma postura frente ao saber" (PIMENTA e ALMEIDA, 2011, p. 
22). $\mathrm{Ou}$ seja, colaborando para uma intervenção pedagógica que garanta a problematização dos saberes e conhecimentos produzidos na universidade e suas contribuições na efetivação de práticas pedagógicas (res)significativas.

As escritas, no processo do Estágio Supervisionado, se constituem como dispositivos formativo relevante para o estudante/estagiário à medida em que permite uma reflexão de si no ato de escrever e narrar as práticas pedagógicas em sala de aula e nas oficinas pedagógicas, construindo um conhecimento acerca de sua atitude e intervenção pedagógica. Desse modo, o estágio se configura como importante campo de conhecimento e eixo curricular nesse processo de formação, ao favorecer que sejam trabalhados aspectos indispensáveis para a construção da identidade docente, como salientam Dias e Pereira (2016).

\section{REFERÊNCIAS}

ALMEIDA, Elmird; GOMES, Marineide de Oliveira; TINÓS, Lúcia M. S. Portfólios de aprendizagem: autonomia, corresponsabilização e avaliação formativa na formação de professores In: GOMES, Marineide de Oliveira. (Org). O estágio na formação de professores: possibilidades formativas entre ensino, pesquisa e extensão. Edições Loyola. São Paulo: 2011. p. 201-222.

ALMEIDA, Maria Isabel de; PIMENTA, Selma Garrido. A construção da pedagogia universitária no âmbito da universidade de São Paulo. In: Pedagogia Universitária: caminhos para a formação de professores. São Paulo: Cortez, 2011.

BASTOS, Tainara dos Santos. Portfólios: um caminho para a reflexão sobre a práxis docente. In: PEREIRA, Áurea da Silva. (Org.). Práticas de pesquisa autobiográfica: letramentos, memórias e narrativas.1 ed. Curitiba, PR: CRV, 2015.p. 61-72.

BERTAUX, Daniel. Narrativas de vida: a pesquisa e seus métodos. Trad. Zuleide A. C; Denise M. G. Lavallée. Natal, RN: EDUFRN; São Paulo, 2010.

BOLÍVAR, Antonio. Dimensiones epistemológicas y metodológicas de lainvestigación (auto)biográfica. In: ABRAHÃO, Maria H. M; PASSEGGI, Maria da Conceição(Org). Dimensões epistemológicas e metodológicas da pesquisa (auto)biográfica: Tomo I. Natal: EDUFRN; Porto Alegre: EDUPUCRS; Salvador: EDUNEB, 2012.

CELLARD, André. A análise documental. In: POUPART, Jean et al. A pesquisa qualitativa: enfoques epistemológicos e metodológicos. Petrópolis, Vozes, 2008.

DELORY-MOMBERGER, Christine. Biografia e educação: figuras do indivíduo projeto. Tradução de Maria da Conceição Passeggi, João Gomes da Silva Neto e Luis Passeggi. Natal, RN: EDUFRN; São Paulo: Paulus, 2008. 
DIAS, Ana R. da Silva; PEREIRA, Aurea da Silva. O estágio no curso de Letras do Departamento de Educação - UNEB - Campus II. In: PEREIRA, Aurea da Silva.; DIAS, Ana R. da Silva; ALMEIDA, Risonete L. de Almeida; CORREIA, Adilson da Silva. (Orgs.) Estágio e Prática Pedagógica: Letramentos e tecnologias digitais na sala de aula. Curitiba: CRV, 2016.

FÁVERO, Altair Alberto; TONIETO, Carina. Educar o educador: reflexões sobre a formação docente. Campinas, SP: Mercado de Letras, 2010.

LIBÂNEO, José Carlos. Adeus professor, adeus professora? Novas exigências educacionais e profissão docente. São Paulo: Cortez, 2004.

LIMA, Maria Socorro Lucena. Estágio e aprendizagem da profissão docente. Brasília: Liber Livro, 2012.

JOSSO, Marie-Christine. Experiências de vida e formação. Tradução José Claudino e Júlia Ferreira. São Paulo: Cortez, 2004.

NÓVOA, António. "Os professores e as histórias de vida". In: NÓVOA, António. (org.). Vidas de professores. 2. ed. Porto: Porto Editora, 2000. p.11-30.

PASSEGGI, Maria da Conceição; ABRAHÃO, Maria Helena M.B; DELORYMOMBERGER, Christine. Reabrir o passado, inventar o devir: a inarrável condição. In: PASSEGGI, Maria da Conceição; ABRAHÃO; Maria Helena M.B (Orgs.). Dimensões epistemológicas e metodológicas da pesquisa (auto)biográfica: Tomo II. Natal: EDUFRN; Porto Alegre: EDUPUCRS; Salvador: EDUNEB, 2012.

PASSEGGI, Maria da Conceição. Mediação biográfica: figuras antropológicas do narrador e do formador. In: PASSEGGI, Maria da Conceição; BARBOSA, Tatyana Mabel Nobre Barbosa (Org.). Memórias, memoriais: pesquisa e formação docente. Natal: EDUFRN; São Paulo: Paulus, 2008.

PEREIRA, Aurea da Silva. Portfólios e memoriais: dispositivos metodológicosno Estágio de Letras. In: PEREIRA, Aurea da Silva; VILELA, Antonio Marcos Maia (Orgs.). Letramentos no Estágio Supervisionado e Formação de Professores. Salvador: EDUNEB, 2013, p.179-203.

PIMENTA, Selma Garrido. Professor reflexivo: construindo uma crítica. In: PIMENTA, Selma Garrido; GHEDIN, Evandro (Orgs.). Professor reflexivo no Brasil: gênese e crítica de um conceito. 2. ed. São Paulo: Cortez, 2002.p. 17-52.

RICOEUR, Paul. Teoria da interpretação: o discurso e o excesso de significação. Trad. Artur Morão. Lisboa: Edições 70, 1976.

SCHÖN, Donald. Educando o profissional reflexivo: um novo design para o ensino e aprendizagem. Trad. Roberto Cataldo Costa. Porto Alegre: Artes Médicas Sul, 2000.

SOUZA, Elizeu Clementino de. Memória educativa: narrativas de formação: recortes de um eu em crescimento e partilha. In: [S.n.]. O conhecimento de si: estágio e narrativas de formação de professores. Rio de Janeiro: DP\&A; Salvador: UNEB, 2006. 


\section{A AUTORA}

Aurea da Silva Pereira é graduada em Letras Vernáculas pela Universidade do Estado da Bahia - UNEB (1996), Especialista em Linguística aplicada ao ensino da Língua Portuguesa pela Universidade Estadual de Feira de Santana -UEFS (1998), Mestre em Educação e Contemporaneidade pela UNEB (2008) e Doutora em Educação e Contemporaneidade pela UNEB (2014). É professora adjunta do Colegiado de Letras, Departamento de Educação - Campus II, da UNEB. Atua na linha de pesquisa 2Letramento, Identidades e Formação de Educadores do Programa de Pós-graduação em Crítica Cultural da UNEB e integra o Grupo de Pesquisa Autobiografia Formação História Oral (GRAFHO); Grupo de Estudos em Resiliência, Educação e Linguagens (GEREL); e Grupo de Estudos e Pesquisas em História, Educação e Gênero (GEPHEG).

E-mail: aureauneb@gmail.com 